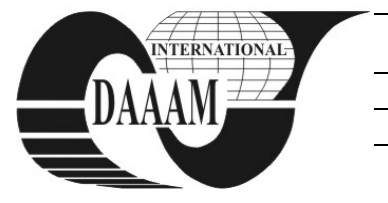

Annals of DAAAM for 2011 \& Proceedings of the 22nd International DAAAM Symposium, Volume 22, No. 1, ISSN 1726-9679 ISBN 978-3-901509-83-4, Editor B. Katalinic, Published by DAAAM International, Vienna, Austria, EU, 2011 Make Harmony between Technology and Nature, and Your Mind will Fly Free as a Bird Annals \& Proceedings of DAAAM International 2011

\title{
STUDIES REGARDING THE USE OF REMOTE SENSING SATELLITE DATA FOR THE IDENTIFICATION OF HEAVY METAL POLLUTION IN AGRICULTURAL FIELDS
}

\author{
DANA, I[ulia] F[lorentina] \& BADEA, A[lexandru]
}

\begin{abstract}
Heavy metal pollution in agricultural fields can be identified using several remote sensing image processing methods. The study aims at the identification of the optimal algorithms and the development of a validated processing work flow in order to detect the contaminated agricultural fields based on remote sensing satellite images. The investigation is performed on data acquired between the years of 2007 and 2011 over a test area-Copsa Mica - previously known as one of the most polluted towns in Europe due to the local industrial activity. The study is conducted on Landsat and SPOT images and the results are validated using ground truth data.

Key words: heavy metal pollution, agricultural field, remote sensing satellite image, multi-temporal analysis, principal component analysis
\end{abstract}

\section{INTRODUCTION}

Copsa Mica is an industrial town that represented for many years one of the most polluted regions in Europe. Air, water, soil and vegetation in Copsa Mica were highly contaminated with heavy metals such as lead, cadmium, zinc and copper. In the last two years, the polluting factories stopped their activity, leading to decreasing levels of contamination.

Remote sensing represents an excellent tool for the detection and monitoring of the areas affected by pollution. This topic has been investigated in numerous scientific studies.

The present study identifies the optimal processing methods for pollution detection based on satellite images and develops a validated work flow that also integrates ground truth data. The proposed approach starts with a large-scale analysis (at regional level) and continues with a detailed analysis at local level.

\section{TEST AREA DESCRIPTION AND INPUT DATA}

Copsa Mica is located slightly north-west from the central part of Romania in the Tarnava hydrographic basin (Figure 1). The multi-spectral analysis was performed on 10 Landsat TM (Thematic Mapper) images acquired between 2009 and 2011, data available from the USGS (webpage http://glovis.usgs.gov/ (C) Landsat images are courtesy of the U.S. Geological Survey).

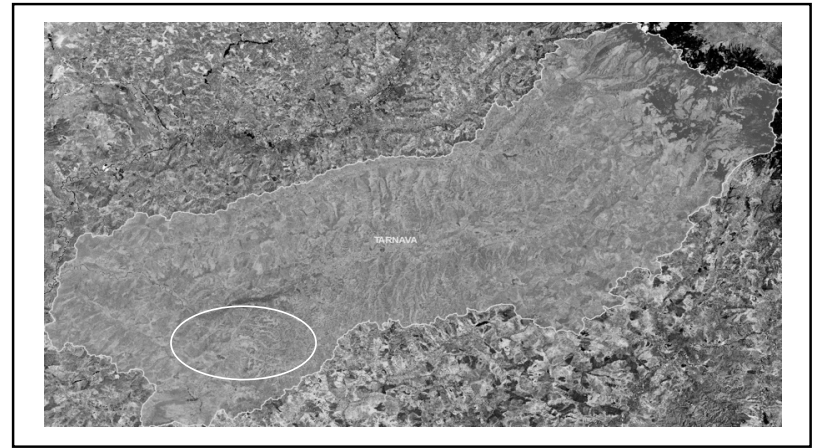

Fig. 1. Test area Copsa Mica, Tarnava hydrographic basin
Landsat TM images have a spatial resolution of $30 \mathrm{~m}$ and 7 spectral bands. A multi-spectral SPOT image (10 m resolution) has been used in the study (C) Astrium Geo-Information Services). Also, 50 samples were gathered in order to determine the concentration of lead, zinc, cadmium, and copper.

\section{METHODOLOGY AND RESULTS}

Before performing the actual multi-spectral analysis, the images were converted into the national projection grid. Also, atmospheric corrections were applied, using the Dark Object Subtraction (DOS) method (Akhter, 2006), (Jiang, 2010).

For heavy metal identification of the contaminated fields, among the widely used processing methods for satellite images acquired by multi-spectral remote sensing sensors there are: principal component analysis (Akhter, 2006), analysis based on the normalised differential vegetation index (NDVI), multitemporal analysis of the spectral signature in the near infrared band (Roy et al., 2010) together with histogram interactive stretching for image enhancement, unsupervised classification, and spectral band arithmetic like subtraction and/or rationing (Kaiser et al., 2008), (Jiang, 2010), (Slonecker et al., 2010). Change detection enables the monitoring of the pollution level.

Principal component analysis proved to be a very useful tool for identifying the contaminated areas, at regional level. The analysis was performed on a SPOT image. The polluted regions (Figure 2 - white areas highlighted by circles) are easy to discriminate among other elements of the satellite image.

The values of the normalised differential vegetation index were computed based on the ten Landsat TM images acquired between July 2009 and August 2011, using the visible red (B3) and the near infrared (B4) spectral bands. The investigation was carried out for each of the fifty samples collected in the field. The results show that the NDVI values are in the range of 0.13 $\div 0.73$, which is a normal interval for vegetation. The diagram of the mean values for each sample is illustrated in Figure 3. Sample no 15 presents the lowest NDVI values that may indicate heavy metal contamination. But many other factors might cause low values for this vegetation index.

Multi-temporal analysis of the spectral response in the nearinfrared band of the Landsat TM sensor offered good results. Nevertheless, a strict separation of areas affected by heavy metal pollution was not possible due to the fact that there is an uncertainty of the discrimination interval between two classes that are similar in terms of radiometry. This issue should be examined carefully in order to avoid confusion. Figure 4 shows the chart of mean values for each sample in the near-infrared spectral band. Mean values of the spectral response increase as the samples are located farther away from the pollution source. Using histogram interactive stretching a spectral interval was defined having a minimum threshold of 67 and a maximum one of 90. The contamination level is higher (darker tones in Figure 5) for the samples that are close to the pollution source.

Change detection was performed based on two Landsat TM images acquired between 2009 and 2011. The spectral response 
for each field sample (in near-infrared) at the beginning of the analysed time interval was higher in comparison with the ones obtained for 2011. This means that the copper contamination has decreased. The results are correct and are explained by the fact that the local polluting factories have stopped their activity.

Unsupervised classification did not offer conclusive results due to the lack of ground truth data collected simultaneously with the acquisition of satellite data.

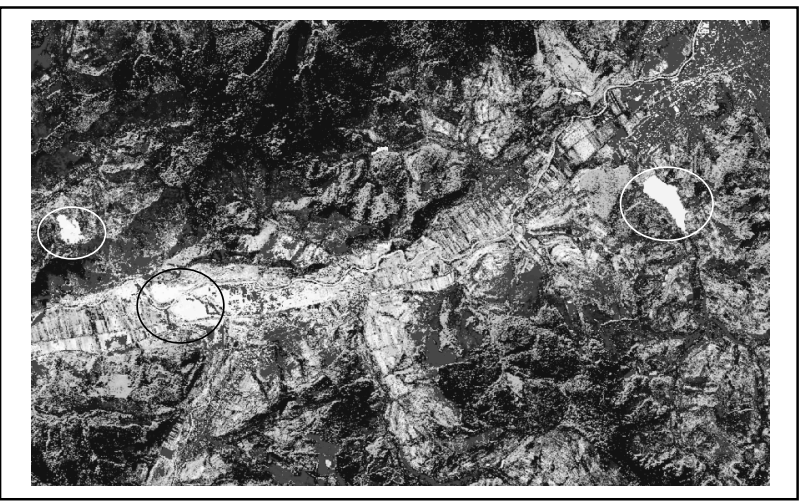

Fig. 2. Principal component analysis for test area Copsa Mica

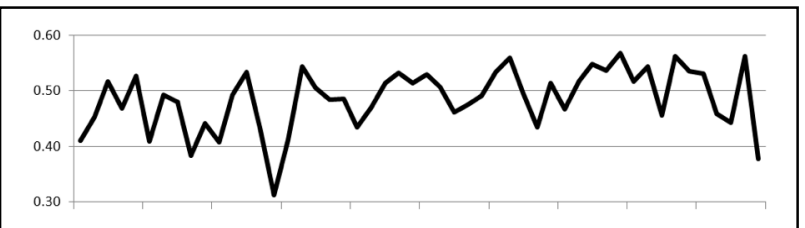

Fig. 3. NDVI mean values computed based on the Landsat TM multi-temporal series for each Copsa Mica field sample

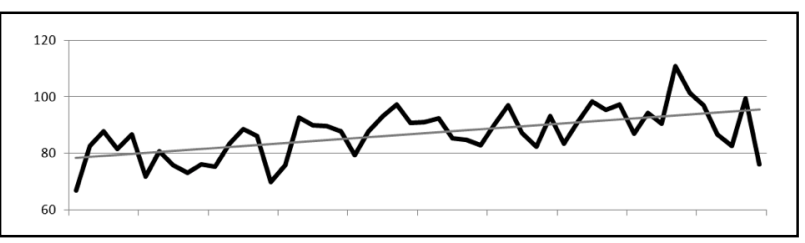

Fig. 4. Mean values of the spectral response in the near-infrared band computed based on the Landsat TM multi-temporal series for each Copsa Mica field sample

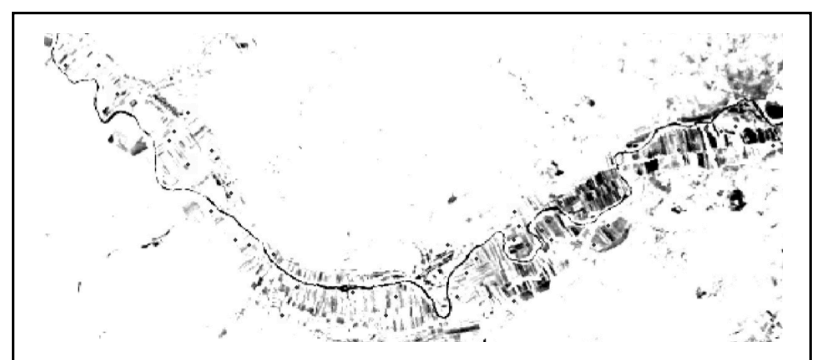

Fig. 5. Analysis of the contamination level for Copsa Mica (darker tones indicate higher contamination level)

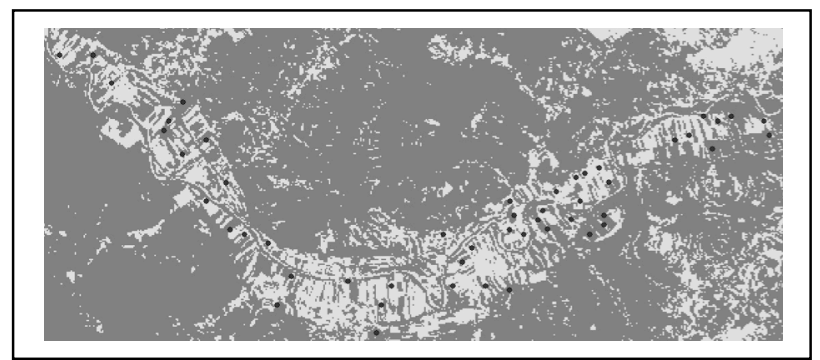

Fig. 6. Change detection based on near-infrared spectral bands for Copsa Mica, July 2009 - June 2011 (lighter tones indicate a decrease with more than $10 \%$ of the spectral response for copper contamination)

\section{CONCLUSION}

The identification and monitoring of heavy metal pollution in agricultural fields using remote sensing satellite images offer satisfactory results. At region level, the most appropriate method is represented by principal component analysis. At local level, a more detailed study can be performed based on the multi-temporal analysis of the spectral response in the nearinfrared band. Change detection proved to be a very efficient method for monitoring the contamination level in time. The other tested methods (unsupervised image classification, analysis based on the normalised differential vegetation index, spectral band arithmetic) did not provide conclusive results.

The limitations of this research study are given by the spatial and spectral resolution of the images that play a decisive role in obtaining accurate results. Moreover, the integration of ground truth data within the processing chain would improve the accuracy of the results. In most of the cases, the results show that the discrimination of the polluted agricultural fields (as a unique class) was very difficult, almost impossible. The spectral signature of the contaminated elements should be determined in advance using auxiliary data in order to avoid confusion with the spectral response of similar classes. Also, the validation of the multi-spectral analysis is mandatory to be performed on the samples collected in the field.

Future research plans involve the use of remote sensing hyper-spectral data acquired in narrower, more sensitive spectral bands that are recommended for the identification and monitoring of heavy metal contamination in agricultural fields.

\section{ACKNOWLEDGEMENTS}

This research was performed in the framework of the "Balance of metals in Romanian agrosystems" (METAGRO) project, funded by the National Authority for Scientific Research, Ministry of Education and Research, under the contract 52175/2008 within the Romanian National Plan for Research, Development and Innovation.

\section{REFERENCES}

Akhter, M. (2006). Remote sensing for developing an operational monitoring scheme for the Sundarban Reserved Forest, Bangladesh, Available from: http://deposit.ddb.de/ cgibin/dokserv?idn=982178700\&dok_var=d1\&dok_ext=pd f\&filename=982178700.pdf Accessed: $2011-09-22$

Jiang, Y. (2010). Identification of Sewage Sludge Injection Application on Harvested Agricultural Fields Using Landsat TM Data, Available from: http://etd.ohiolink.edu/ sendpdf.cgi/Jiang\%20Yitong.pdf?toledo1290201856 Accessed: 2011-09-16

Kaiser, M., Aboulela, H., El-Serehy, H. A. \& Ezz Edin, H. (2008). Spectral Enhancement of the SPOT Imagery Data to Assess Marine Pollution near Port Said, Egypt, Proceedings of Progress in Electromagnetics Research Symposium, 2-6 July 2008, Cambridge, USA, ISSN 15599450, ISBN 978-1-934142-06-6, pp. 746-753, published by The Electromagnetics Academy, Cambridge

Roy, P.S., Dwivedi, R.S. \& Vijayan, D. (2010). Remote Sensing Applications, published by National Remote Sensing Centre, Indian Space Research Organisation, ISBN 978-81909460-0-1, Hyderabad, India

Slonecker, T., Fisher, G., Aiello, D. \& Haack, B. (2010). Visible and Infrared Remote Imaging of Hazardous Waste: a Review. Remote Sensing, Vol. 2, No. 11, November 2010, 2474-2508, ISSN 2072-4292

*** (2011) http://glovis.usgs.gov/ - U.S. Geological Survey (USGS), Earth Resources Observation and Science Center (EROS), USGS Global Visualization Viewer, Accessed on: 2011-09-28 